\title{
SELECTIVE PREDATION AND THE INTENSITY OF SELECTION ACTING UPON THE LATERAL PLATES OF THREESPINE STICKLEBACKS
}

\author{
D. W. HAGEN* and L. G. GILBERTSON \\ College of Fisheries, University of Washington, Seattle, Washington 98195
}

Received 9.v.72

\section{Summary}

\begin{abstract}
Sticklebacks in Lakes Wapato and Chelan are far inland and highly isolated from other populations. They live about one year. Rainbow trout prey on sticklebacks most heavily during the winter, and this predation is random on males and females and on the three plate morphs. However, trout show strong selective predation on sticklebacks with respect to plate number. The selective advantage of seven plated sticklebacks under predation is highly significant and consistent over three years. The frequency of seven plated adults in Lake Wapato was 56 per cent. in 1968, but increased to 65 per cent. in 1969 and has since remained at about 62 per cent. This large increase coincides with the time interval when predation was heaviest and when selective predation favouring sevens was greatest. The heritabilities for number of plates and gill rakers are high, and so the values obtained for the increase in mean relative fitness show that natural selection is acting strongly on these traits. Predation acting on the variation in plate number and food specialisation acting on gill rakers are two of the major selective agents.
\end{abstract}

\section{INTRODUCTION}

Threespine sticklebacks (Gasterosteus aculeatus) are renowned for their great phenotypic variation, especially so for the number of bony plates on the sides of the body and the number of gill rakers (Bertin, 1925; Heuts, 1947a; Munzing, 1963; Miller and Hubbs, 1969; Paepke, 1970; Hagen and Gilbertson, 1972). The causes of this variability are complex and poorly known. Both marine and freshwater populations of this small fish occur along the coasts of the northern hemisphere, and hybridisation between the two maintains some of the variation (Munzing, 1963; Hagen, 1967). But in the Pacific Northwest of America hybridisation is largely confined to narrow zones in some coastal streams and apparently introgression does not occur (Hagen, 1967; Hagen and McPhail, 1970; Hagen and Gilbertson, 1972).

Heuts $(1947 b, 1956)$ found some correlations between plate number, temperature tolerance and the ability to osmoregulate, suggesting that natural selection may be acting on plates with respect to these environmental factors. Recent evidence strongly suggests that natural selection is one of the principal causes of the phenotypic variation in sticklebacks (Hagen and McPhail, 1970) and that selective predation by predatory fish is at least one of the major selective agents causing large differences in plate number among freshwater populations (Hagen and Gilbertson, 1972; Moodie, 1972), whereas feeding specialisation to diverse environments is one of the major factors acting upon the variation in gill rakers.

* Present address: Biology Department, University of New Brunswick, Fredericton, New Brunswick, Canada. 
In this paper we give further evidence for selective predation on sticklebacks with respect to their plate number. The evidence was obtained from an examination of 4559 stomachs of rainbow trout (Salmo gairdneri) taken from a freshwater lake in Washington State. In conjunction with this we have also estimated the overall intensity of selection acting upon the variation in plates and gill rakers in the lake during 1969, as measured by the survival from offspring to adults in a single generation.

For any meaningful interpretation of the selection acting upon these quantitative traits their heritability must be known. Several estimates have been made with stocks from Lake Wapato (Hagen, 1972) where the present study was conducted. The heritability for gill rakers is $0.58 \pm 0.56$. The two estimates for number of plates are $0.50 \pm 0.043$, and $0.83 \pm 0.033$, depending upon the temperature at which the offspring are reared. Another estimate for the heritability of plate number is $0.84 \pm 0.039$, and was determined from a series of crosses from five populations. There is thus a large store of additive genetical variance available in these populations for response to selection.

As is the case for all studies in ecological genetics, here too a brief description of the population structure and the distribution of phenotypes in the lake is necessary before the evidence for selective predation and the intensity of selection can be evaluated.

\section{Materials AND MEthods}

Lake Wapato is located on the eastern slopes of the Cascade Mountains in the desert of central Washington. The lake is 87 hectares in size and is adjacent to Lake Chelan, a very large glacial lake of 13,408 hectares. The sticklebacks in these lakes are highly isolated from other populations because they are east of the mountains, whereas sticklebacks are otherwise confined to the lowlands along the Pacific coast. All drainages into the lakes come from snowfields and glaciers in the mountains and the one outlet into the Columbia River, in Lake Chelan, drops vertically 135 metres through an impassable gorge. The distance to the ocean along the river is 805 kilometres.

Rainbow trout are stocked in the lake by the State authorities for anglers. The trout and sticklebacks occur in large numbers and when the work began no other fish were present, but later small numbers of catfish (Ictalurus) and sunfish (Lepomis) were introduced. The lake water is usually clear with visibility extending to about 3 metres.

Sampling stations for sticklebacks were established at three sites spaced out round the lake. Samples were made with a 5-metre seine (two-man) with a mesh size of $5 \mathrm{~mm}$. We have given evidence elsewhere that this method yields random samples (Hagen and Gilbertson, 1972). The samples were taken between April and October of 1968, 1969 and 1970 and preserved in 10 per cent. formalin. Samples of sticklebacks for estimating age from the annuli of otoliths were frozen in polythene sacs until ready for use.

Four thousand three hundred and eighty-three rainbow trout were caught by anglers fishing from dinghies in the open water of the lake from May through June; the entrails of the trout were preserved in large containers of 15 per cent. formalin provided for the anglers. These samples 
of trout cover the same three years as do the above samples of sticklebacks taken from the lake. One sample of 176 trout was taken during the winter (December) of 1968 using monofilament gill-nets.

Three plate morphs occur in the lake as they do in other freshwater sites (Hagen and Gilbertson, 1972). We have named these the low, partial and completely plated morphs to distinguish them from the marine trachurus and hybrids. The low plated morph has anterior plates only, the partially plated morph has anterior plates and a caudal keel of plates, and the completely plated one has a continuous series of bony plates along the sides of the body (fig. 1). The three morphs are controlled by major genes
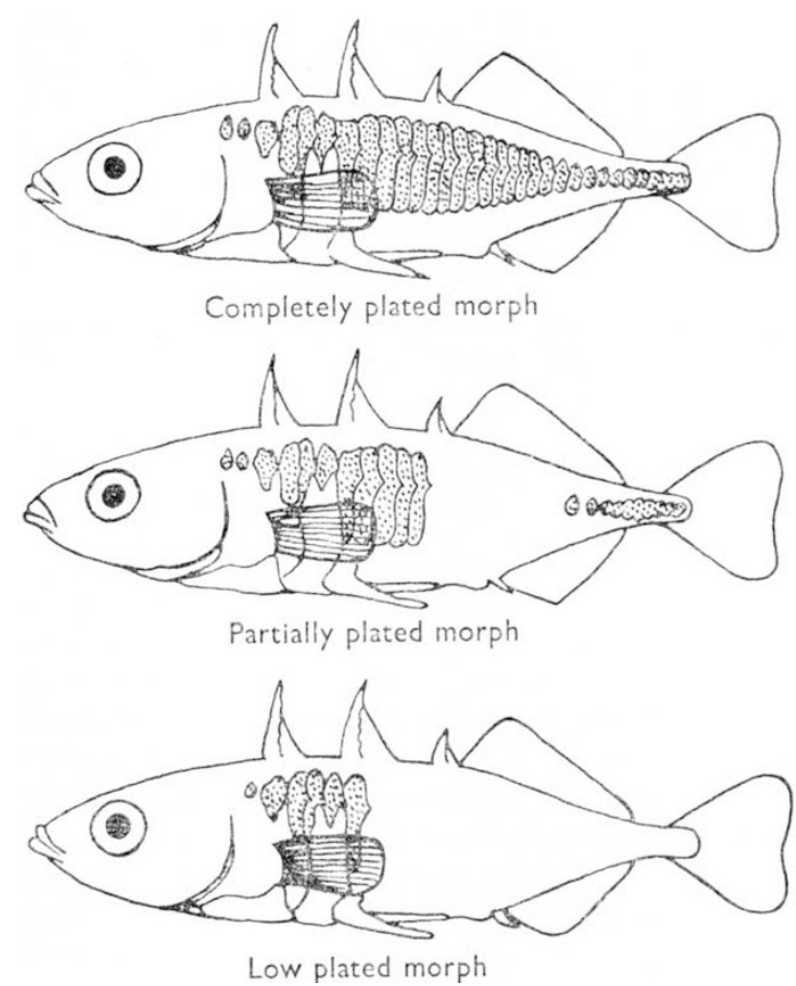

Fig. 1.-Plate morphs of Gasterosteus aculeatus; plates are shown with stippling.

(Hagen and Gilbertson, 1973). The number of plates in each morph varies widely. In Lake Wapato plate number varies from three to 14 in the low plated morph, and from three to 27 in the partially plated one. As mentioned in the Introduction this quantitative variation in plate number within each morph has a high heritability.

Individuals were scored for standard length, sex, plate number, plate morphs, and number of gill rakers according to the criteria of Hagen and Gilbertson (1972). The number of plates and gill rakers are fully developed in this population when the offspring reach a size of $28 \mathrm{~mm}$, which corresponds to an age of about $2 \frac{1}{2}$ months (Hagen, 1972). Methods for preparing and scoring annuli of otoliths (sagitta) for age estimates follow those of Jones and Hynes (1950). 
Counts of plates on sticklebacks removed from trout were only made on those taken from the oesophagus and anterior portion of the stomach. These are always completely intact and show no obvious signs of digestion. We find as did Moodie (personal communication) that sticklebacks from the posterior part of the stomach and intestine are too digested to give reliable counts of plates. After staining with alizarin (Red $\mathrm{S}$ ) in 2 per cent. $\mathrm{KOH}$, the plates were counted and the sex was recorded.

\section{Results}

\section{(A) Life history and population structure}

Reproduction begins in Lake Wapato in April, when large numbers of sticklebacks move into the shallows of the lake, and reaches a peak through May and June. As is usual for sticklebacks, adults die after reproduction and their corpses litter the shallows in July and August.

The distribution of size classes is unimodal in April and May, but becomes sharply bimodal in June when offspring are first taken (fig. 2).

TABLE 1

Sex ratio for adult and fry Gasterosteus, and chi-square analyses for departure from a $1: 1$ ratio $(P=$ probabilities $)$

\begin{tabular}{|c|c|c|c|c|}
\hline & & $\begin{array}{l}\text { Sample } \\
\text { size }\end{array}$ & $\chi_{(1)}^{2}$ & $P$ \\
\hline Adults & $\begin{array}{l}\text { qo } \\
\text { tot }\end{array}$ & $\left.\begin{array}{l}2590 \\
2071\end{array}\right\}$ & $57 \cdot 79$ & $<0.001$ \\
\hline Fry & $\begin{array}{l}\text { 우 } \\
30\end{array}$ & $\left.\begin{array}{l}1578 \\
1032\end{array}\right\}$ & $114 \cdot 22$ & $<0.001$ \\
\hline
\end{tabular}

As adult mortality progresses, the larger size classes decrease in frequency, and in September the distribution is again unimodal. Approximately the same histograms were obtained over three years, indicating the sticklebacks live one year. Independent estimates of age were obtained by scoring the annuli of otoliths, which also indicate the sticklebacks live one year (fig. 2). However, about 8 per cent. of the adults aged as 1 year old by size are scored as 2 years old by otoliths. We collected an additional 85 corpses of postreproductive adults in July and all were scored as I year old by their otoliths. So at least 92 per cent. of the individuals live only one year and possibly as much as 8 per cent. survive two years. The length of life clearly varies among populations (Greenbank and Nelson, 1959; van Mullem and van der Vlugt, 1964; Moodie, 1970), and it is relevant that the sticklebacks in Wapato with a short length of life are also unusually small (mean size of adults is $43 \mathrm{~mm}$.).

It is difficult to obtain an unbiased estimate of the sex ratio of adults because males establish nesting colonies in the shallows of the lake. However, there are significantly more females in our samples from the colonies (table 1). This excess of females is probably real because there are also more females in the offspring samples, and the departure from equality is highly significant (table 1).

In no instance was there a significant difference among sites in the lake for frequencies of plate morphs, number of plates, or gill rakers of the sticklebacks and so the data for the three sites are pooled. Not only are 

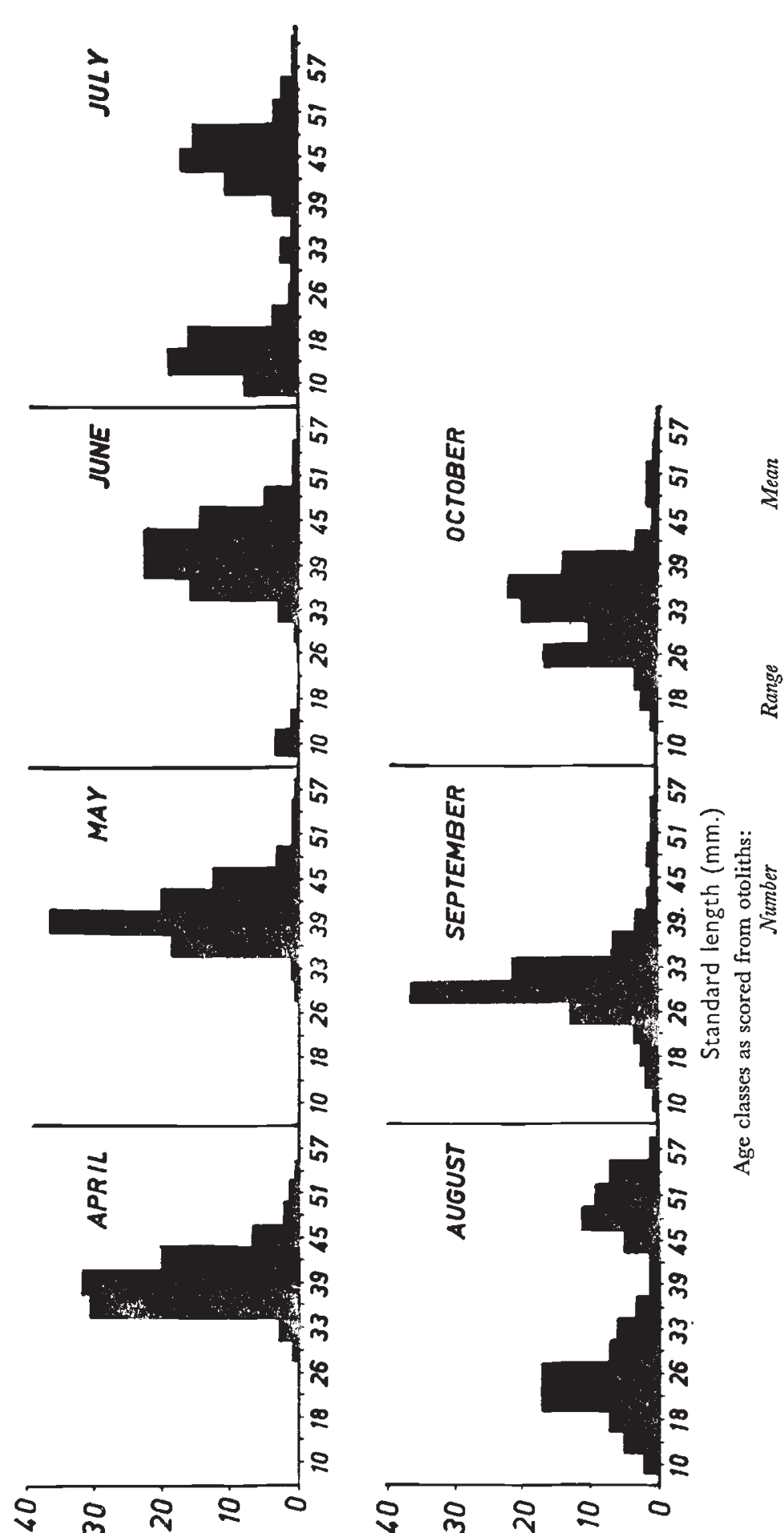
the frequencies of the plate morphs stable among sites, but table 2 shows they are also stable over the 3 years, the differences being non-significant. Morph frequencies differ significantly between the sexes (table 2), but the differences are very small.

Since the completely plated morph is at a very low frequency in the lake, constituting much less than 1 per cent. of the population, plate number for the low and partially plated morphs only is shown. The sexes do not differ for this trait (table 3). The distribution for the number of plates is skewed toward higher numbers, but about 90 per cent. of the population has counts from six to eight plates and there is a very large mode of 61 per cent. at seven plates. The plate number of adults differs significantly over the three years $\left(\chi_{(20)}^{2}=93 ; \mathrm{P}<0.001\right)$. In particular there is a very large difference between 1968 and 1969, when the frequency of seven plated fish increased from 56 to 65 per cent. (table 3). Like the adults, the distribution for the offspring also differs significantly over years $\left(\chi_{(12)}^{2}=150 \cdot 66\right.$; $\mathrm{P}<0.001)$, and they too show a very large increase in number of seven

TABLE 2

Plate morphs: frequencies for the sexes of Gasterosteus (above), and frequencies over three years (below); chi-square analyses for homogeneity between sexes and among years $(d . f .=$ degrees of freedom)

\begin{tabular}{|c|c|c|c|c|c|c|c|c|c|}
\hline & \multicolumn{6}{|c|}{ Morphs } & \multirow[b]{3}{*}{$x^{2}$} & \multirow[b]{3}{*}{ d.f. } & \multirow[b]{3}{*}{$\mathrm{P}$} \\
\hline & \multicolumn{2}{|c|}{ Low } & \multicolumn{2}{|c|}{ Partial } & \multicolumn{2}{|c|}{ Complete } & & & \\
\hline & $\mathrm{N}$ & $\%$ & $\mathrm{~N}$ & $\%$ & $\mathrm{~N}$ & $\%$ & & & \\
\hline \multicolumn{10}{|l|}{ Sex } \\
\hline 우우 & 4038 & $96 \cdot 9$ & 125 & $3 \cdot 0$ & 5 & $0 \cdot 1$ & 11.95 & 2 & $0.01>\mathrm{P}>0.001$ \\
\hline$\sigma^{\circ}$ & 2735 & $95 \cdot 4$ & 130 & $4 \cdot 5$ & 2 & $0 \cdot 1$ & & 2 & $0.01>1>0.001$ \\
\hline \multicolumn{10}{|l|}{ Years } \\
\hline 1968 & 1671 & $96 \cdot 0$ & 66 & $3 \cdot 8$ & 4 & $0 \cdot 2$ & & & \\
\hline 1969 & 1388 & $95 \cdot 6$ & 62 & $4 \cdot 3$ & 1 & $0 \cdot 1$ & $2 \cdot 39$ & 4 & $0.70>P>0.50$ \\
\hline 1970 & 1148 & $95 \cdot 7$ & 51 & $4 \cdot 2$ & 1 & $0 \cdot 1$ & & & \\
\hline
\end{tabular}

plated fish from 45 per cent. in 1968 to 60 per cent. in 1969. Since the offspring in 1968 become the adults of 1969 (i.e. they constitute one generation), selection must have favoured seven plated fish very strongly during the winter of 1968. In fact, a comparison between the offspring and adults in each generation shows that individuals with counts less than seven decrease in frequency whereas those with counts of seven or eight increase (table 3 ). The differences between adults and offspring within each year will then of course be significantly different as is shown (table 3). The large increase in frequency of sevens is maintained in both the adults and offspring in 1970 (and to the present, unpublished data). The closely corresponding changes in frequencies between adults and offspring are to be expected since the heritability for plate number is high. These changes in plate number are very relevant to several points considered later.

As with plates, the number of gill rakers do not differ between the sexes (table 4), but unlike plate number the distribution is nearly normal. Gill rakers also show a significant difference between 1968 and 1969 (table 5) with an increase in the mean and a decreased variance, and these changes 


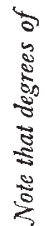

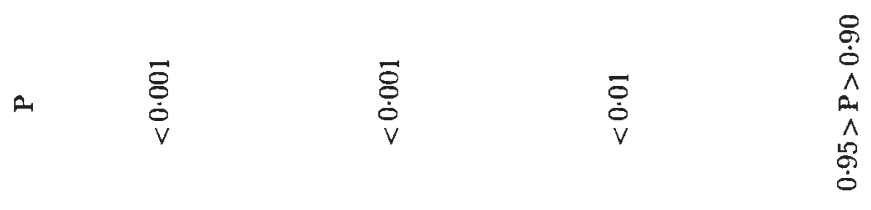

$\stackrel{\phi}{\dot{0}}$
$\hat{1}$
$\hat{\leftrightarrow}$
$\hat{\leftrightarrow}$
$\dot{0}$

รัป

รูำ

$\stackrel{\leftrightarrow}{i} \quad \sigma$

$\infty$

$+$

2

$x \quad \stackrel{8}{\frac{0}{6}}$

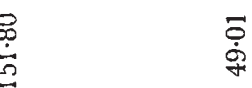

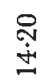

$\stackrel{8}{\stackrel{8}{r}}$

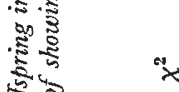

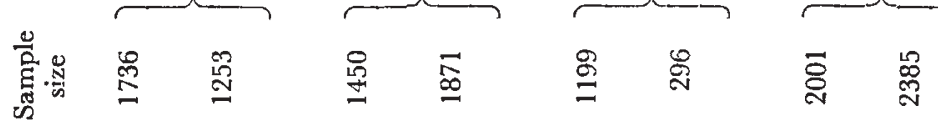

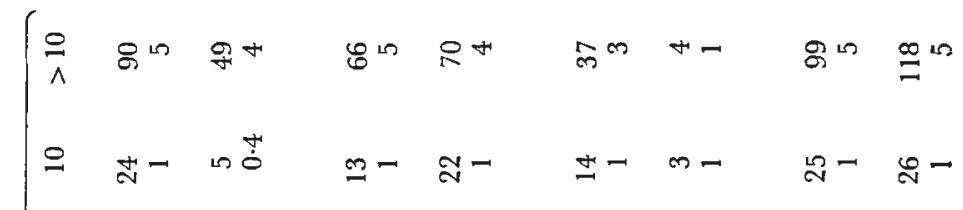

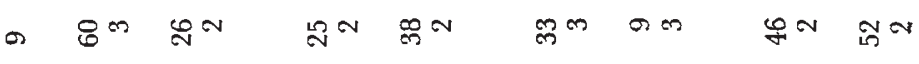

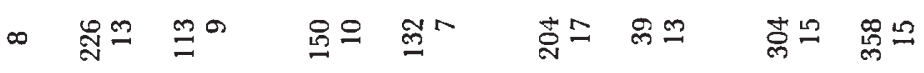

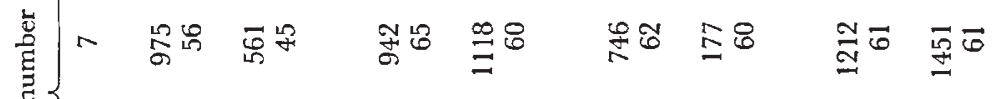

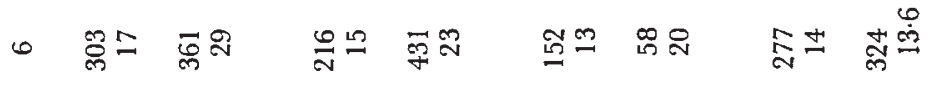

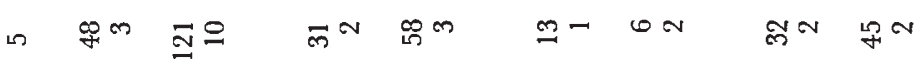

+

m 00 n

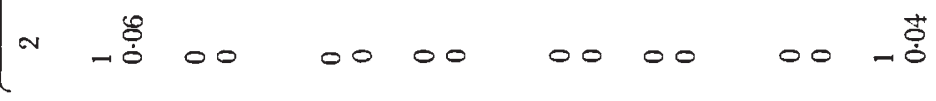

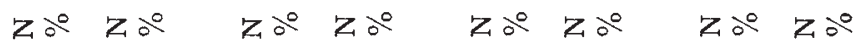
电完 
TABLE 4

Gill rakers: frequencies for adult male and female Gasterosteus, and chi-square for homogeneity between the two

Gill raker number

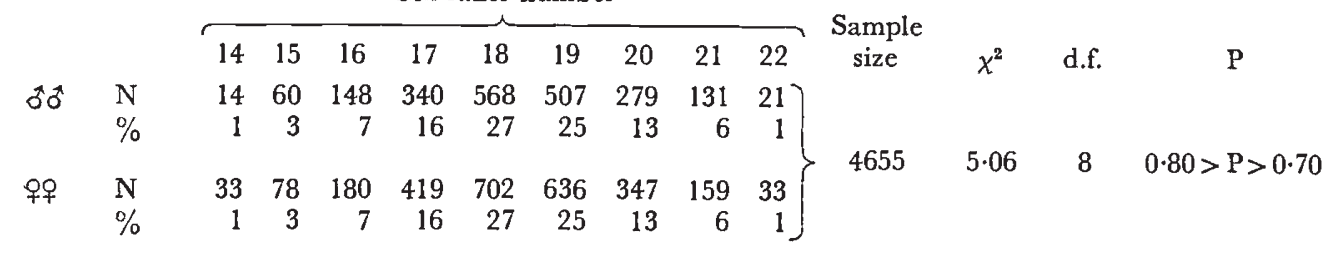

TABLE 5

Gill rakers: means and variances in three years for Gasterosteus and significance tests for differences among years (hsd = critical value for means; if the difference between any two means exceeds this, they differ significantly)

\begin{tabular}{|c|c|c|c|c|c|c|}
\hline & Mean & S.D. & $\begin{array}{c}\text { Sample } \\
\text { size }\end{array}$ & $\begin{array}{c}\text { Variance } \\
\text { ratio }\end{array}$ & $F_{(0 \cdot 05)}$ & $\begin{array}{l}\text { Tukey's test } \\
\text { hsd at } 0.05\end{array}$ \\
\hline 1968 & $17 \cdot 822$ & 1.670 & $1821\}$ & 1.66 & $1 \cdot 13$ & \\
\hline 1969 & $18 \cdot 707$ & 1.296 & 1664\{ & & & $0 \cdot 122$ \\
\hline 1970 & $18 \cdot 651$ & 1.232 & 1201 & $1 \cdot 10$ & $1 \cdot 10$ & \\
\hline
\end{tabular}

TABLE 6

Trout predation: analysis of Gasterosteus eaten by rainbow trout in Lake Wapato for three years. See text

Total trout examined

$\begin{array}{cccc}\text { Spring } & \text { Winter } & \text { Spring } & \text { Spring } \\ 1968 & 1968 & 1969 & 1970\end{array}$

Number trout with food

$\begin{array}{llll}1126 & 176 & 1821 & 1436\end{array}$

Number trout with food

Number trout with sticklebacks
Mean sticklebacks per trout

$\begin{array}{cccc}621 & 144 & 959 & 703 \\ (55 \%) & (82 \%) & (53 \%) & (49 \%)\end{array}$

$\begin{array}{cccc}77 & 115 & 86 & 69 \\ (12 \%) & (80 \%) & (9 \%) & (10 \%)\end{array}$

Sex of eaten sticklebacks

3

$4 \cdot 8$

$2 \cdot 4$

Sex of eaten sticklebacks

우우

45

115

54

71

Morph frequencies of eaten sticklebacks

Lows
Partials

23

101

31

41

are maintained in 1970 (and to the present). Both number of plates and gill rakers thus show large changes over the same time interval.

(B) Trout predation on sticklebacks

Of the trout that had food in their stomachs between 9 and 12 per cent. ate sticklebacks in the spring samples, and they averaged between 2.4 and 3 sticklebacks in their stomachs (table 6). Predation appears to be much heavier in the winter, however, as 80 per cent. ate sticklebacks at that time and they also averaged more sticklebacks in their stomachs ( 4.8 per stomach). This increased predation largely arises because during the winter trout as 
small as $22 \mathrm{~cm}$. feed on sticklebacks, whereas in the summer only trout $35 \mathrm{~cm}$. or larger feed on them and there are relatively few large trout in the lake.

Females predominate in the samples taken from trout stomachs (table 6). But, as was shown, there are significantly more females in the lake so this may not indicate heavier predation on them. The sex ratio is homogeneous for samples taken from the trout $\left(\chi_{(3)}^{2}=6.02 ; 0.20>P>0 \cdot 10\right)$ and are thus pooled. Taking the observed sex ratio in the lake as an expected value (2071 males: 2590 females) there is then no evidence for selective predation on the females $\left(\chi_{(1)}^{2}=2 \cdot 40 ; 0 \cdot 20>P>0 \cdot 10\right)$.

Frequencies for the three plate morphs in the trout stomachs are also homogeneous over years (table $6 ; \chi_{(3)}^{2}=3.3,0.50>\mathrm{P}>0.30$ ), and so the combined data are compared with frequencies of the morphs in the lake, as there is no spatial or temporal heterogeneity. Predation on the morphs is apparently random $\left(\chi_{(1)}^{2}=3.02 ; 0.10>\mathrm{P}>0.50\right)$.

Although the frequencies for plate number do not differ between sexes or among sites, there are large differences over the three years. We must therefore compare the samples of sticklebacks from trout stomachs for each year with the corresponding samples from the lake. Clearly the trout are not taking a random sample of the sticklebacks with respect to their plate number and although this selective predation is not quite significant in the spring of 1968 it is highly significant in the winter, and in 1969 and 1970 (table 7). The pattern of selective predation is consistent and striking over the 3 years. This can be evaluated by comparing the frequencies (in percentages) of sticklebacks with different plate counts from trout stomachs with those sampled from the lake over the same interval of time (table 7). Seven plated sticklebacks are consistently preyed upon at a lower frequency than expected. This selective advantage of sevens is least in the spring of 1968 at 7 per cent., and is greatest in the winter of 1968 at 30 per cent. and the spring of 1969 at 40 per cent. Individuals with counts less than seven and those with nine plates are at a strong disadvantage under predation. For example, sticklebacks with five plates average a 12 per cent. disadvantage over years. On the other hand, eights appears to be neutral with respect to predation.

\section{(C) The intensity of selection}

These sticklebacks are unusually favourable for estimating the intensity of selection because nearly all the fish live only one year and they can reliably be scored for number of plates and gill rakers at the early age of about $2 \frac{1}{2}$ months (Hagen, 1973).

A sample of 3096 offspring was taken in September 1969, when they varied from 30 to $34 \mathrm{~mm}$. size. A sample of 3236 adults was taken in midJune of the following year, just before the onset of post-reproductive mortality. Thus the time interval nearly spans one generation of selection but will not of course account for survival from egg to about $2 \frac{1}{2}$ months of age. It should be clear that the samples of offspring and adults are taken from a single generation; although the heritabilities for plates and gill rakers are high, it would not be valid to estimate the intensity of selection using offspring and adults from different generations unless the heritability were equal to one because they would then be exposed to different environments during development and it would be impossible to separate selective mortality from environmentally induced variation. 


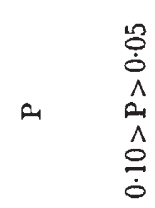

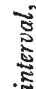

苛

हัँ

赵

竞

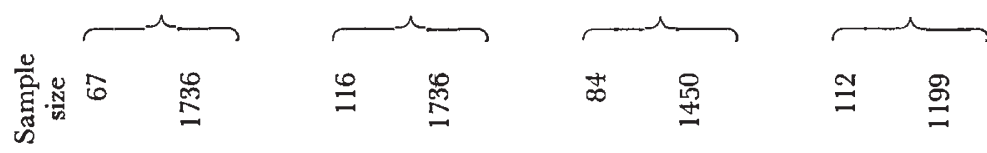

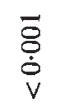<smiles>[SiH2]=[SiH2]</smiles>

$\stackrel{\mathscr{\infty}}{\stackrel{\circ}{=}}$

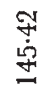

$\stackrel{\stackrel{4}{\oplus}}{\dot{\infty}}$

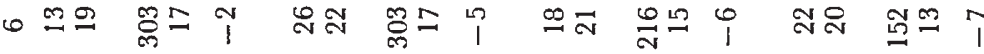

n

MHoO

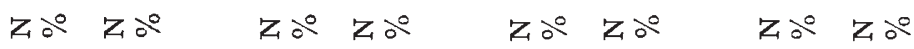

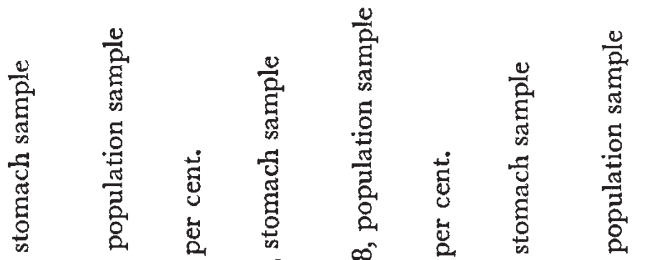

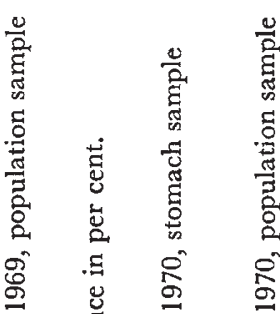

舫

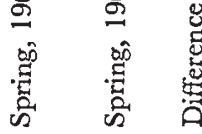

क्षे

कृ

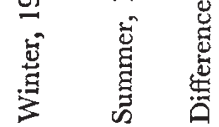

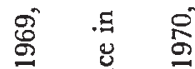

晷

踗 营

葛

กิ

a 
In contrast with the previous data, plates were counted on both sides of each individual and summed, so the plate number will in general be twice that usually shown (table 8 ). Gill rakers are tedious to count, especially when very large samples are required, as is the case for estimating the intensity of selection. Counts are therefore from the left side only, as usual.

\section{TABLE 8}

Relative fitness, change in mean relative fitness $\left(\Delta \bar{w} / \bar{w}=V_{w} / \bar{w}^{2}\right)$, and intensity of selection $(I=1-\bar{w})$ for lateral plates and gill rakers of sticklebacks, Lake Wapato. The statistics are: $\bar{X}$ and $\bar{X}^{\prime}$, $V_{x}$ and $V_{w}^{\prime}$, means and variances for traits before and after selection; $\bar{w}$ and $\bar{w}^{\prime}$ and $V_{w}$ and $V_{w}^{\prime}$, means and variances for fitness before and after selection

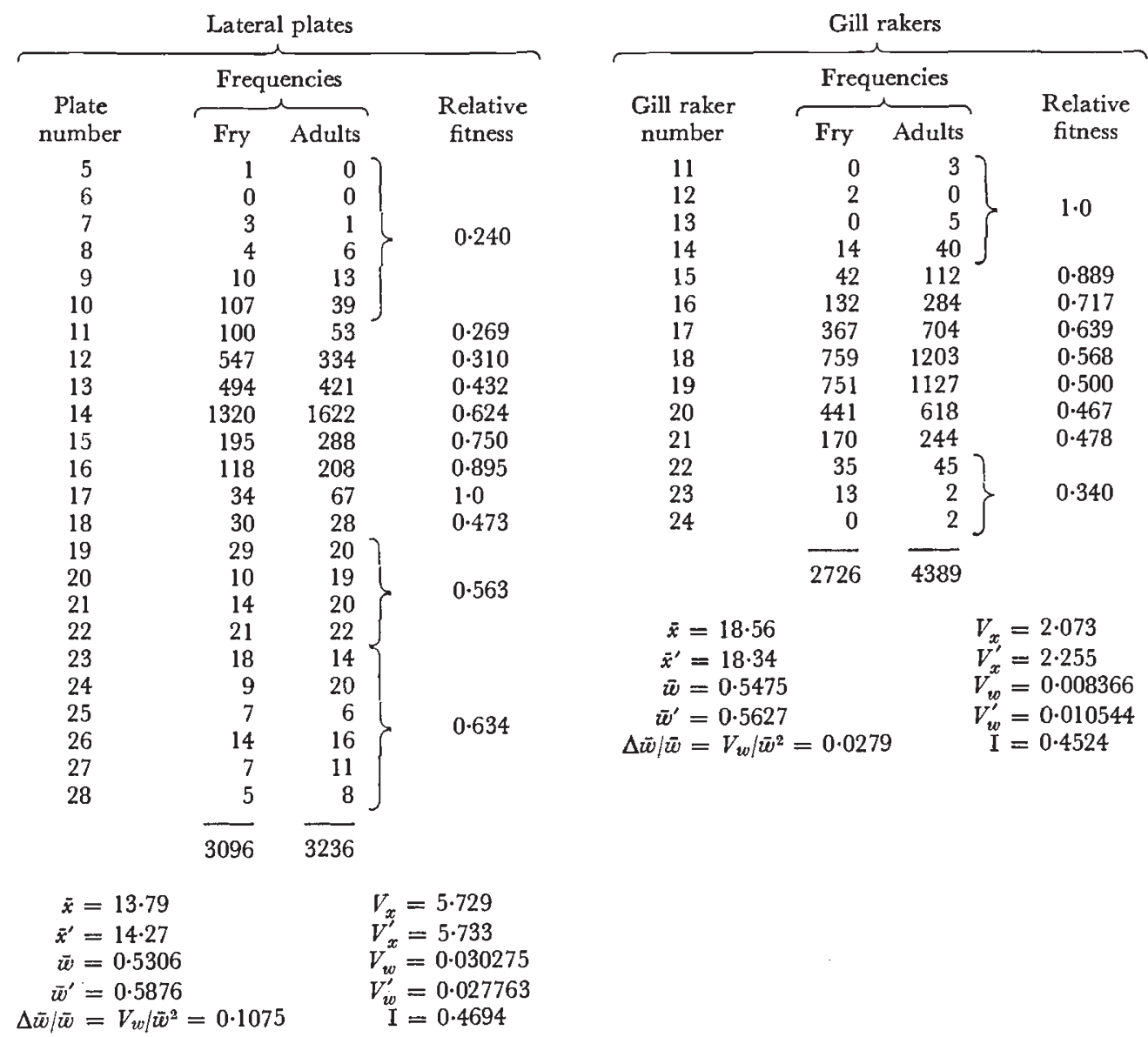

We have evidence from large samples in the lake that counts do not differ between sides (fluctuating asymmetry), so counts from one side would not affect our conclusions.

Haldane (1954) and Van Valen (1965) showed that the intensity of selection may be evaluated as $I=1-\bar{w}$, $\bar{w}$ being the mean fitness. This estimate gives the proportion of selective deaths relative to the phenotype having the greatest survival from offspring to adult (the optimum phenotype). It is the same as the genetic load but measures survival of phenotypes 
rather than genotypes, and as O'Donald says (1970b), it may be called the phenotypic load.

O'Donald (1968, 1970a, 1970b, 1971) showed the intensity of selection as measured above has undesirable properties. It is estimated relative to an optimum phenotype, but the optimum may often not exist as for example with directional selection. Even with stabilising selection the determination of an optimum is subject to sampling error and unless samples are very large a misplaced optimum will seriously affect the results. Indeed, the optimum is an hypothetical quantity that selection can never achieve because there will always be variation round the mean, environmental and genetic. Rather than measure the amount by which fitness is depressed below an optimum as does the value $I$, O'Donald has taken the increase in mean relative fitness $\left(\Delta \bar{w} / \bar{w}=V i \bar{w} / \bar{w}^{2}\right.$, where $V w$ is the variance in fitness $)$ as the best index for measuring the intensity of selection because it gives the proportionate amount by which selection has raised the mean fitness and so is not a purely hypothetical quantity as is $I$. We have estimated both indices of selection; even though the intensity is less meaningful it may be useful as a comparison where others have used it.

The data and results are shown in table 8 . The values for the change in mean relative fitness (and intensity of selection) show that selection is acting strongly upon the variation in number of plates and gill rakers. Given the selective predation acting upon plate number the large value is not too surprising. The selection on plate number is largely stabilising as the optimum phenotype, at 17 plates (asymmetric individuals with eight plates on one side and nine on the other), is close to the population mean. The selection on gill rakers is strongly directional with the optimum far removed from the population mean. The optimum is at lowest counts and fitness progressively declines with increasing numbers. This is a very surprising result as it suggests the population is not in equilibrium. In any case, the distribution of fitness for gill rakers nicely shows us how arbitrary is the choice of an optimum phenotype, as the optimum must be at some low and unknown value.

The indices of selection we have used only measure survival from offspring to adult and of course take no account of differential mating or fecundity. Sampling error for frequencies of the phenotypic classes will inflate our estimates of selection, but on the other hand the estimates may be minimal because they take no account of survival from egg to about $2 \frac{1}{2}$ months of age.

It is of interest to obtain the correlation coefficients between the number of plates and gill rakers for offspring and for adults because this may indicate whether or not fitnesses for the two traits interact. The correlation coefficient for the offspring is $r=0.051$ and for the adults is $r=0.025$ (data for plate number were log-transformed). Both are non-significant $(P>0.05)$, suggesting that selection is acting independently on the two traits for if the fitness were interacting there should be a correlation between the two traits in the adults.

\section{Discussion}

Rainbow trout in Lake Wapato have shown a highly significant selective predation on sticklebacks in three consecutive years. This selective predation 
has consistently fallen heaviest on individuals with less than seven plates and those with nine, whereas seven plated fish have had a selective advantage. In the spring of 1968 the advantage of seven plated fish was at 7 per cent. but during the winter and following spring this greatly increased to 30 and 40 per cent.

It is significant that in the spring of 1968 the frequency of seven plated adults was only 56 per cent. and 45 per cent. in their offspring. But there was a great increase to 65 per cent. in the following spring of 1969. Clearly selection must have strongly favoured seven plated individuals during the winter to increase their frequency within one generation from 45 per cent. in the offspring to 65 per cent. in the following spring when they had grown to adults. It was in fact during the winter of 1968 and the spring of 1969 that we obtained the greatest values for selective predation favouring seven plated sticklebacks. It was also during the winter that trout predation upon sticklebacks was greatest, as was also found by Foerster (1968) and Moodie (1972). Since this large increase in frequency of seven plated sticklebacks in Lake Wapato coincides with the strongest selective predation favouring sevens, and with the most intense trout predation during the winter, it is very likely the cause was the selective predation. But it is impossible to prove. In any case the frequency of seven plated fish was maintained at 62 per cent. in 1970 (and to the present time).

Why then was the frequency of seven plated fish at so low a value in 1968 when the work began? Lake Wapato was poisoned with rotenone by the State authorities in 1957, and since 1965 they have stocked the lake with about 51,000 trout fry each year (Fred Holmes, State Fisheries, personal communication). The only source from which sticklebacks could recolonise Lake Wapato is Lake Chelan (see Materials and methods). Water is pumped up to Wapato from Chelan during the spring, for use in irrigation, through a discharge line with a diameter of $75 \mathrm{~cm}$. Although we took no sticklebacks in our nets suspended at the outlet during this study, live sticklebacks are sometimes pumped into the lake (U.S. Bureau Land Reclamation, Manson). The frequency of seven plated sticklebacks in Chelan is 46 per cent. (Hagen and Gilbertson, 1972). It is thus very likely that Wapato was recolonised by sticklebacks from Chelan after Wapato was poisoned, which accounts for the low frequencies of seven plated fish in 1968.

The mean for gill rakers in Chelan is $19 \cdot 4$, which is greater than that in Wapato. Means for gill rakers are significantly greater in large glacial lakes than they are in streams or marshes, which is apparently a specialisation for gathering food (Hagen and Gilbertson, 1972). Chelan is a very large glacial lake and Wapato a much smaller, marshy lake. Immigrants from Ghelan into Wapato may thus be subjected to selection for a decrease in number of gill rakers, and indeed we found strong directional selection acting upon gill rakers such that individuals with lowest counts have the greater fitness. The data for gill rakers therefore supports the conclusion that Wapato was recently colonised from Lake Chelan.

Moodie (1972) studied predation by cut-throat trout on sticklebacks in Mayer Lake, British Columbia, over three years. He found that these trout also selectively prey upon sticklebacks with different plate counts. In the lake where trout predation is heavy, 73 per cent. of the sticklebacks are seven plated, but in streams round the lake where trout are absent, the 
frequency drops abruptly to 2 per cent. Selective predation has thus been found in two widely separated localities in the Pacific Northwest, and in a recent geographic survey (Hagen and Gilbertson, 1972) we found a very close correlation between the distribution of predatory fish and modes at seven plates in populations of Gasterosteus. In that study we also found that Lake Summit, like Wapato, had been poisoned and there too the evidence strongly suggests that the frequency of seven plated sticklebacks rapidly increased after the lake was re-stocked with trout.

The values obtained for the increase in mean relative fitness show that very strong natural selection is acting upon the variation in number of plates and gill rakers of sticklebacks, and apparently this acts in part through the agents of selective predation on plate number and feeding specialisation on gill rakers. Any attempts to explain the variability of these traits in freshwater populations of Gasterosteus that does not take account of natural selection will fall short. Thus the hypothesis of Miller and Hubbs (1969), that this variability is maintained by introgression and nothing more than this, can be rejected.

Acknowledgments.-We are very grateful to Mr David Semler for valuable assistance in the field. We thank him and Mrs Patricia Moodie for aid in scoring many sticklebacks. Drs G. E. E. Moodie, J. D. McPhail and Joseph Felsenstein have discussed many aspects of the work with us and given assistance in many ways. We wholeheartedly thank them. Professors P. M. Sheppard and Bryan Clarke, and Drs Peter O'Donald and Moodie reviewed the manuscript. We owe a debt for their generous criticism. The research was supported by a grant (GB7686) from the National Science Foundation to one of us (D. W. H.)

\section{REFERENGES}

BERTIN, L. 1925. Recherches bionomiques, biométriques et systématiques sur les Épinoches (Gastérosteidés). Ann. Inst. Oceanograph. Monaco, N.S., 2, fasc. 1.

Foerster, r. E. 1968. The sockeye salmon. Fish. Res. Bd. Canada, Bull., 162, 422 pp.

GREENBANK, J., AND NELSON, P. R. 1959. Life history of the threespine stickleback Gasterosteus aculeatus Linnaeus in Karluk Lake and Bare Lake, Kodiak Island, Alaska. U.S. Fish Wildl. Serv. Fish. Bull., 59, 537-559.

HAGEN, D. w. 1967. Isolating mechanisms in threespine sticklebacks (Gasterosteus). F. Fish. Res. Bd. Canada, 24, 1637-1692.

HAGEN, D. W. 1972. Inheritance of numbers of lateral plates and gill rakers in Gasterosteus aculeatus. Heredity, 30, 301-312.

HAGeN, D. W., AND GIlbertson, L. G. 1972. Geographic variation and environmental selection in Gasterosteus aculeatus L. in the Pacific Northwest, America. Evolution, 26, 32-51.

HAGEN, D. W., AND GILbERTson, L. G. 1973. The genetics of plate morphs in Gasterosteus aculeatus. Heredity (in press.)

HAGEN, D. W., AND MCPHAil, J. D. 1970. The species problem within Gasterosteus aculeatus on the Pacific Coast of North America. 7. Fish. Res. Bd. Canada, 27, 147-155.

haldane, J. B. s. 1954. The measurement of natural selection. Proc. Ninth Int. Congr. Genet., 1, 480-487.

Heuts, M. J. 1947a. The phenotypical variability of Gasterosteus aculeatus L. populations in Belgium. Mededel. Koninkl. Vlaam. Akad. Wetenschap., 9, 5-63.

HEUTS, M. J. 1947b. Experimental studies on adaptive evolution in Gasterosteus aculeatus I. Evolution, 1, 89-102.

HeUts, м. J. 1956. Temperature adaptation in Gasterosteus aculeatus L. Publ. della Stazione Zool. die Napoli, 28, 44-61.

JoNEs, J. W., AND HYNEs, н. B. N. 1950. The age and growth of Gasterosteus aculeatus, Pygosteus pungitius and Spinachia vulgaris, as shown by their otoliths. F. Anim. Ecol., 19, 59-73. 
MILlER, R. R., AND HUBBS, c. L. 1969. Systematics of Gasterosteus aculeatus, with particula reference to intergradation and introgression along the Pacific Coast of North America: a commentary on a recent contribution. Copeia, 1969, 52-69.

MOODIE, G. E. 1970. Predation as a mechanism in the evolution of an unusual population of sticklebacks in the Queen Charlotte Islands, Canada (Pisces: Gasterosteidae). Ph.D. Thesis, Dept. of Zool., Univ. of Alberta, Edmonton, Alberta. 86 pp.

MOodiE, G. E. 1972. Predation, natural selection and adaptation in an unusual threespine stickleback. Heredity, 28, 155-168.

MULLEN, P. VAN, AND VLUGT, J. VAN DER. 1964. On the age, growth and migration of the anadromous stickleback Gasterosteus aculeatus L. investigated in mixed population. Arch. Neerl. Zool., 16, 111-139.

MUNZING, J. 1959. Biologie, variabilität. und genetik von Gasterosteus aculeatus L. (Pisces)untersuchungen im elbegebiet. Intern. Rev. d. gesamten Hydrobiol., 44, 317-382.

O'DONALD, P. 1968. Measuring the intensity of natural selection. Nature, 220, 197-198.

O'DONALD, P. 1970a. Measuring the change of population fitness by natural selection. Nature, 227, 307-308.

o'DonaLD, P. 1970 b. Change of fitness by selection for a quantitative character. Theor. Pop. Biol., 1, 219-232.

O'DONALD, P. 1971. Natural selection for quantitative characters. Heredity, 27, 137-153.

PAEPKE, H. J. 1970. Studien zur ökologie, variabilität und population struktur des dveistach ligen und neunstach ligen sticklings. II. Die variabität der lateralbeschildung von Gasterosteus aculeatus L. in einer brandenburgischen intergradationszone und ihre zoogeographisch-historischen Hintergründe. Beiträge Zur Tierwelt Der Mark, 7, 5-48.

VAN VALEN, L. 1965. Selection in natural populations. III. Measurement and estimation. Evolution, 19, 514-558. 